\title{
Standardizing Sign-out With I-PASS Handoff in Family Medicine Residency
}

Kento Sonoda, MD | Lindsay Nakaishi, MD, MPH, DipABLM | Cynthia Salter, PhD, MPH PRiMER. 2021;5:8.

Published: 2/4/2021 | DOI: 10.22454/PRiMER.2021.678175

\section{Abstract}

Introduction: Handoff miscommunications are a leading cause of medical errors. A structured handoff is an effective communication tool. We introduced the I-PASS Handoff Bundle for resident sign-out in the inpatient setting. We aimed to reduce preventable adverse events and unexpected floor calls while also improving residents' confidence and preparedness to care for patients overnight.

Methods: We conducted an observational study at a single-site family medicine residency between April 2019 and March 2020. Residents received trainings in the I-PASS standardized handoff through didactic lectures and on-the-job sessions in September and November 2019. We evaluated the effectiveness of the I-PASS Handoff Bundle by comparing pre- and postimplementation data including number of medical errors and unexpected floor calls, along with residents' reported levels of preparedness and confidence to care for patients overnight.

Results: Prior to the I-PASS intervention, more than half of resident surveys included at least one unexpected floor call whereas postintervention about one-third of resident surveys included unexpected floor calls $(P<.05)$. However, the intervention did not significantly affect residents' confidence level in caring for patients overnight and residents' rating of the usefulness of anticipatory guidance for managing night floor calls. We did not identify any medical errors related to communication issues at patient handoff within the family medicine service.

Conclusion: I-PASS intervention significantly reduced unexpected floor calls. However, the intervention did not improve residents' reported confidence and preparedness to care for patients overnight.

\section{Introduction}

Communication error is a leading cause for sentinel events. ${ }^{1}$ Ineffective or incomplete transitions of care can negatively impact both patients and physicians by contributing to potential miscommunication and errors, or by compromising resident confidence. ${ }^{2}$ For example, a 2009 systematic review found that omitted information and incorrect information were common at patient care handoff. ${ }^{3}$

Patient handoffs between residents have become more frequent because of duty hour restrictions. ${ }^{4}$ The Accreditation Council for Graduate Medical Education (ACGME) mandates resident training in effective transitions of patient care and emphasizes the importance of managing handoffs to comply with new 
recommendations for resident duty hours. ${ }^{5}$ Residency programs in other subspecialties, including pediatrics and internal medicine, have implemented standardized transition-of-care processes for the inpatient setting, although assessment of these quality improvement measures remains ongoing and data from family medicine are lacking. ${ }^{6-9}$

Our family medicine residency program did not have a standardized overnight sign-out process. We selected the I-PASS Handoff Bundle because it is the most validated method for handoffs. ${ }^{6,10}$ The I-PASS mnemonic provides a framework for patient handoff as follows: Illness severity, Patient summary, Action list, Situation awareness and contingency planning, Synthesis by receiver. ${ }^{11}$ In a 2014 multicenter study, the I-PASS Handoff Bundle implementation was shown to reduce preventable adverse events. ${ }^{6}$ We hypothesized that a standardized handoff process for resident sign-out would (1) reduce preventable unexpected floor calls, (2) improve residents' confidence to care for patients overnight through better handoffs, and (3) reduce preventable adverse events.

\section{Methods}

We conducted an observational study with 29 family medicine residents in a family medicine residency training program at an urban hospital. ${ }^{12}$ The Institutional Quality Improvement Review Committee approved this study.

For the intervention, we introduced the I-PASS structure through two 20-minute didactic lectures and on-the-job training sessions in September and November 2019. After each session, we also sent a follow-up email with a summary of the training content. A one-page summary of sign-out template and I-PASS instructions was attached to the wall in the inpatient team staff room.

Preimplementation data were collected for 27 weeks from April through September 2019. All components of the resident handoff bundle were implemented at the end of September along with a follow-up session in November. We collected postimplementation data for 24 weeks from October 2019 through March 2020. We collected data via an anonymous survey completed by night float residents to quantify unexpected floor calls, and measure residents' preparedness and confidence in responding to floor calls. When night float residents had unexpected floor calls, they also quantified the contents under the following categories: pain, blood pressure, and others. We asked night float residents to complete the anonymous questionnaire every night shift when possible. Some nights, two residents completed surveys for the same shift. To increase the number of respondents, we used several approaches: setting a survey collection box in the on-call room for residents to reduce access barriers, sending a reminder as part of weekly emails from the program director to all residents, and sending additional reminders to residents prior to the on-call shift. The sign-out template and survey are available on the STFM Resource Library. ${ }^{13}$

We evaluated the effectiveness of I-PASS implementation by comparing the pre- and postimplementation data including number of unexpected floor calls and medical errors. We also evaluated residents' reported levels of confidence and preparedness with Likert scale responses 1 to 5 ( $1=$ =very unconfident or not at all helpful and $5=$ very confident or extremely helpful).

For patient outcomes, we measured total number of medical errors during the two survey collection periods, using the incidence/occurrence system in our institution. Two physician reviewers further classified all medical errors into subtypes of medical errors related to communication: within family medicine (FM) service, between FM service and different services, between FM service and floor nurses, and at the institutional level (eg, medication reconciliation, paging system). We reviewed only events reported by physicians in the department of family medicine and excluded medical events for which communication at transitions of care of care would not be a factor (eg, falls). Evidence was not available to categorize errors as adverse or near misses. 


\section{Results}

Prior to the I-PASS intervention, more than half of resident surveys $(56 / 103)$ included at least one unexpected floor call, whereas postintervention about one-third of resident surveys (46/127) included unexpected floor calls $(P<.05 ;$ Table 1$)$. Night floor calls regarding blood pressure and pain remained unchanged despite listing pain and blood pressures on anticipatory guidance as a template in order to remind resident physicians (Table

2). The intervention did not significantly affect residents' confidence level in caring for patients overnight (Table 3). It also did not improve residents' rating of the usefulness of anticipatory guidance for managing night floor calls (Table 4). Further, analysis of patient outcomes did not identify any medical errors related to transition-ofcare communication within the FM service (Table 5). Instead, we found that most medical errors were related to communication between FM service and other hospital services or floor nurses (Table 5).

\section{Conclusions}

The intervention of the standardized I-PASS approach to handoffs, coupled with resident training and reenforcement, significantly reduced unexpected floor calls in the short term, however additional evaluation is merited. Additional qualitative exploration of resident confidence level and preparedness may be needed. Because we did not track the number of questionnaires per residents, our findings might not fully represent all residents' experiences. Additionally, night team residents care for patients whom day team residents do not follow, yet residents do not provide patient handoffs for these patients. This might affect interpretation of the effectiveness of I-PASS implementation. Our small study size did not allow assessment of impact on patient outcomes. However, our findings reaffirm the usefulness of I-PASS for improving communication at transitions of care and demonstrate that introducing I-PASS during regular didactic trainings at a family medicine residency is both feasible and beneficial. Our next step is to explore transition-of-care issues with other health professionals. Coordinating care with other hospital services and floor nurses is critical for family physicians who care for patients with multiple chronic conditions.

\section{Tables and Figures}

Table 1: Surveys Reporting Unexpected Floor Calls (\%)*

\begin{tabular}{|c|c|c|c|}
\hline & \multicolumn{2}{|c|}{ Unexpected Floor Call } & \multirow{2}{*}{$\begin{array}{c}\text { Number of Surveys } \\
\text { Completed }\end{array}$} \\
\hline & Yes & No & \\
\hline Preimplementation & $56(54.4)$ & $47(45.6)$ & 103 \\
\hline
\end{tabular}

${ }^{*} P<.05$

Table 2: Contents of Unexpected Floor Calls

\begin{tabular}{|l|c|c|c|c|}
\hline & Pain & Blood Pressure & Others* & Number of Unexpected Floor Calls \\
\hline Preimplementation & 51 & 30 & 92 & 173 \\
\hline Postimplementation & 44 & 41 & 76 & 161 \\
\hline
\end{tabular}

*Others include tachycardia, hyperglycemia, fever, nausea, and shortness of breath 
Table 3: Confidence to Care for Patients Overnight*

\begin{tabular}{|l|c|c|c|c|c|c|}
\hline \multirow{2}{*}{} & \multicolumn{2}{|c|}{ PGY-1 } & \multicolumn{2}{c|}{ PGY-2 } & \multicolumn{2}{c|}{ PGY-3 } \\
\cline { 2 - 7 } & $\begin{array}{c}\text { Number of } \\
\text { Respondents }\end{array}$ & $\begin{array}{c}\text { Mean } \\
(\mathbf{9 5 \%} \mathrm{Cl})\end{array}$ & $\begin{array}{c}\text { Number of } \\
\text { Respondents }\end{array}$ & $\begin{array}{c}\text { Mean } \\
(\mathbf{9 5 \%} \mathrm{Cl})\end{array}$ & $\begin{array}{c}\text { Number of } \\
\text { Respondents }\end{array}$ & $\begin{array}{c}\text { Mean } \\
(\mathbf{9 5} \% \mathbf{C I})\end{array}$ \\
\hline Preimplementation & 52 & $\begin{array}{c}3.92 \\
(3.75,4.1)\end{array}$ & 24 & $\begin{array}{c}4.25 \\
(4.01,4.49)\end{array}$ & 27 & $\begin{array}{c}4.18 \\
(4.01,4.29)\end{array}$ \\
\hline Postimplementation & 63 & $\begin{array}{c}3.82 \\
(3.7,3.96)\end{array}$ & 60 & $\begin{array}{c}4.25 \\
(4.12,4.38)\end{array}$ & 4 & $4(4)$ \\
\hline
\end{tabular}

*Likert scale: $1=$ very unconfident; $5=$ =very confident.

Table 4: Helpfulness of Anticipatory Guidance to Manage the Night Floor Calls*

\begin{tabular}{|l|c|c|c|c|c|c|}
\hline \multirow{2}{*}{} & \multicolumn{2}{|c|}{ PGY-1 } & \multicolumn{2}{c|}{ PGY-2 } & \multicolumn{2}{c|}{ PGY-3 } \\
\cline { 2 - 7 } & $\begin{array}{c}\text { Number of } \\
\text { Respondents }\end{array}$ & $\begin{array}{c}\text { Mean } \\
(95 \% \mathrm{Cl})\end{array}$ & $\begin{array}{c}\text { Number of } \\
\text { Respondents }\end{array}$ & $\begin{array}{c}\text { Mean } \\
(95 \% \mathrm{Cl})\end{array}$ & $\begin{array}{c}\text { Number of } \\
\text { Respondents }\end{array}$ & $\begin{array}{c}\text { Mean } \\
(95 \% \mathrm{Cl})\end{array}$ \\
\hline Preimplementation & 52 & $\begin{array}{c}3.69 \\
(3.51,3.88)\end{array}$ & 22 & $\begin{array}{c}3.95 \\
(3.68,4.23)\end{array}$ & $\begin{array}{c}3.63 \\
(3.37,3.89)\end{array}$ \\
\hline Postimplementation & 63 & $\begin{array}{c}3.98 \\
(3.86,4.11)\end{array}$ & 60 & $\begin{array}{c}4.33 \\
(4.17,4.49)\end{array}$ & 4 \\
$(1.93,3.07)$
\end{tabular}

*Likert scale: $1=$ not at all helpful; $5=$ extremely helpful.

Excluded two resident physicians who answered not applicable.

Table 5: Patient Outcomes: Incidence of Medical Errors and Medical-Error Subtypes Before and After Implementation of the I-PASS Handoff Bundle

\begin{tabular}{|l|c|c|}
\hline \multicolumn{1}{|c|}{ Variable } & Preimplmenetation & Postimplementation \\
\hline Overall medical errors & 6 & 10 \\
\hline Subtypes of Medical Error Related to Communication & & \\
\hline Within family medicine (FM) service & 0 & 0 \\
\hline Between FM service and different services & 1 & 3 \\
\hline Between FM service and floor nurses & 3 & 3 \\
\hline At the institutional level & 2 & 4 \\
\hline
\end{tabular}

\section{Acknowledgments}

Presentation: This study was presented at the University of Pittsburgh Medical Center Annual GME Quality and Safety Symposium, September 4, 2019, in Pittsburgh, Pennsylvania. This study was also presented at the Society of Teachers of Family Medicine Virtual Annual Conference, August 24-28, 2020.

Acknowledgments: The authors thank Barry Coutinho and Jacqueline Weaver-Agostoni for administrative support.

\section{Corresponding Author}

Kento Sonoda, MD

5215 Center Avenue, Pittsburgh, PA. 412-623-2287, Fax: 412-623-6629.

kento.sonoda.md@gmail.com 


\section{Author Affiliations}

Kento Sonoda, MD - Department of Family Medicine, University of Pittsburgh Medical Center Shadyside, Pittsburgh, PA

Lindsay Nakaishi, MD, MPH, DipABLM - Department of Family Medicine, University of Pittsburgh Medical Center Shadyside, Pittsburgh, PA

Cynthia Salter, PhD, MPH - University of Pittsburgh Graduate School of Public Health, Pittsburgh, PA

\section{References}

1. The Joint Commission. Sentinel Event Statistics Data. https://www.jointcommission.org/resources /patient-safety-topics/sentinel-event/. Accessed December 14, 2020.

2. Horwitz LI, Moin T, Krumholz HM, Wang L, Bradley EH. Consequences of inadequate sign-out for patient care. Arch Intern Med. 2008;168(16):1755-1760. doi:10.1001/archinte.168.16.1755

3. Riesenberg LA, Leitzsch J, Massucci JL, et al. Residents' and attending physicians' handoffs: a systematic review of the literature. Acad Med. 2009;84(12):1775-1787. doi:10.1097/ACM.0b013e3181bf51a6

4. DeRienzo CM, Frush K, Barfield ME, et al; Duke University Health System Graduate Medical Education Patient Safety and Quality Council. Handoffs in the era of duty hours reform: a focused review and strategy to address changes in the Accreditation Council for Graduate Medical Education Common Program Requirements. Acad Med. 2012;87(4):403-410. doi:10.1097/ACM.0b013e318248e5c2

5. Nasca TJ, Day SH, Amis ES Jr; ACGME Duty Hour Task Force. The new recommendations on duty hours from the ACGME Task Force. N Engl J Med. 2010;363(2):e3. doi:10.1056/NEJMsb1005800

6. Starmer AJ, Spector ND, Srivastava R, et al; I-PASS Study Group. Changes in medical errors after implementation of a handoff program. N Engl J Med. 2014;371(19):1803-1812. doi:10.1056/NEJMsa1405556

7. Lescinskas E, Stewart D, Shah C. Improving Handoffs: Implementing a Training Program for Incoming Internal Medicine Residents. J Grad Med Educ. 2018;10(6):698-701. doi:10.4300/JGME-D-18-00244.1

8. Tufts LM, Damron CL, Flesher SL. Addition of CORES to the I-PASS Handoff: a resident-led quality improvement study. Pediatr Qual Saf. 2020;5(1):e251. doi:10.1097/pq9.0000000000000251

9. O'Toole JK, Starmer AJ, Calaman S, et al. I-PASS mentored implementation handoff curriculum: champion training materials. MedEdPORTAL. 2019;15(1):mep_2374-8265.10794. doi:10.15766/mep_2374-8265.10794

10. Starmer AJ, O'Toole JK, Rosenbluth G, et al; I-PASS Study Education Executive Committee. Development, implementation, and dissemination of the I-PASS handoff curriculum: A multisite educational intervention to improve patient handoffs. Acad Med. 2014;89(6):876-884.

doi:10.1097/ACM.0000000000000264

11. Agency for Healthcare Research and Quality. TeamSTEPPS. https://www.ahrq.gov/teamstepps /index.html. Accessed December 14, 2020.

12. University of Pittsburg Medical Center. UPMC Shadyside Family Medicine Residency Program Home Page. https://shadyside.familymedicine.pitt.edu. Accessed December 14, 2020.

13. Sonoda K, Nakaishi L, Salter C. Sign-Out with I-PASS Handoff. STFM Resource Library. https://resourcelibrary.stfm.org/viewdocument/sign-out-with-i-pass-handoff1?CommunityKey=2751b51d-483f-45e2-81 de-4faced0a290a\&tab=librarydocuments. Published December 8, 2020. Accessed February 2, 2021.

Copyright $(2021$ by the Society of Teachers of Family Medicine 